\title{
A Study of Young Children's Coordinated Movement-The Effects of a Rhythmic-Play Exercise Program on Physical-Expression Ability
}

\author{
Eri Yoshimi1 ${ }^{12}{ }^{*}$, Teruo Nomura ${ }^{1}$, Noriyuki Kida ${ }^{1}$ \\ ${ }^{1}$ Graduate School of Science and Technology, Kyoto, Japan \\ ${ }^{2}$ Tokiwakai College Early Childhood Education, Osaka, Japan \\ Email: *e-yoshimi@tokiwakai.ac.jp
}

How to cite this paper: Yoshimi, E., Nomura, T., \& Kida, N. (2021). A Study of Young Children's Coordinated Movement-The Effects of a Rhythmic-Play Exercise Program on Physical-Expression Ability. Advances in Physical Education, 11, 118-134.

https://doi.org/10.4236/ape.2021.111009

Received: January 8, 2021

Accepted: February 23, 2021

Published: February 26, 2021

Copyright $\odot 2021$ by author(s) and Scientific Research Publishing Inc. This work is licensed under the Creative Commons Attribution International License (CC BY 4.0).

http://creativecommons.org/licenses/by/4.0/

\section{(c) (i) Open Access}

\begin{abstract}
The current study examined young children's physical-expression ability-defined here as social development that enables communication with other children through the experience of an exercise program-by observing movement changes before and after the exercise program. The study participants were 29 three-year-old children, 44 four-year-old children, and 33 five-year-old children, for a total of 106 people. During the exercise intervention period, the children took part in a coordinated movement program focusing on rhythmic play for six minutes a day. The results of a motor skills test showed that those of the four- and five-year-old children improved, while those of the three-year-old children partially improved. In relation to physical-expression ability, the evaluation scores for motion, space, dynamics, and time significantly increased in all age groups. The current study shows that the exercise program experience led to social development that transcended age difference via movement-based communication, in addition to improving young children's motor skills and physical-expression ability.
\end{abstract}

\section{Keywords}

Young Children, Physical-Expression Ability, Social Development, Coordinated Movement, Motor Skills

\section{Introduction}

\section{Young Children's Motor Skills and Physical Expression Ability}

Physical expression by playing with rhythm is an opportunity to move to the rhythm and express oneself. By expressing this self, the range of one's con- 
sciousness extends to other people. Physical expression is thought to support mental and physical development and promote activity in young children.

The following studies have analyzed the effects of dance instruction, including rhythmic exercises and aerobics, on motor skills. Evridiki et al. (2004) studied the effects of developmentally appropriate musical and movement programs on the motor abilities of preschoolers aged four, five, and six years. They reported that children who engaged in the programs improved their motor skills by jumping and dynamic balancing, while rhythmic activities played a crucial role in motor skills. Tomita et al. (2014) showed that aerobic exercise and unique rhythmic exercises designed to enhance muscle strength and flexibility improved young children's physical fitness. This study reported the effect of jumping at a constant rhythm by engaging in continuous two-footed jumping. Takenawa et al. (2008) observed that children moved happily during aerobic lessons that incorporated coordinated movements designed for three-, four-, and five-year-olds and described possible movements among young children. Thus, although instructions and programs have enhanced the sense of rhythm in smooth forms of movement such as dance instruction, rhythmic exercise, and aerobics, few studies have investigated rhythmic-exercise instructions based on coordinated movements or revealed their effects on motor skills. In this study, we created and implemented a coordination exercise program centered on rhythmic play and examined its effects.

According to the Japanese Ministry of Education, Culture, Sports, Science and Technology (MEXT, 2002), there has been a trend toward polarizing children's physical fitness and motor skills. Commentators have noted a decline in young children's ability to manipulate their bodies; this skill is related to the development of the nervous system, which controls the body. For example, skipping ropes is declining among young children. According to Ikai (1963), physical fitness has both physical and mental components that are classified as behavioral and defensive fitness, respectively. The function of behavioral fitness consists of muscle strength, agility and speed, balance and motor coordination, endurance, and flexibility. Behavioral fitness is associated with motor skills and the physical ability to move the body, and it can be further broken down into physical fitness (from an energy perspective, which is a component of muscle strength, endurance, and power), and physical fitness (from a cybernetics perspective, which includes coordination and integration). As Ikai (1972) has explained, the muscle force mainly restricted by nerves is the coordination and integration ability, expressed through the relationship between nerves and muscles; it is essential to strengthen it during the development of motor ability in the nervous system function. As the Scammon growth curve illustrates, the nervous system undergoes remarkable development in early childhood. It is particularly important for young children to acquire the ability to move skillfully and develop their coordination and integration abilities as these skills are needed to strengthen physical fitness and motor skills in early childhood. According to Takai (2007), coordina- 
tion and integration ability is determined by complicated and intertwined psychological and social-environmental factors, including exercise play and the home and preschool environments. Psychological and social factors interact in the development of coordination and integration ability, while the developing nervous system functions enrich the daily activities of young children, whose mental and physical characteristics are rapidly evolving.

According to Ueda (2008), in contrast to the coordination and integration ability (choseiryoku) conceptualized and studied in Japan, the motor ability of the nervous system is seen as coordination ability (koordination), based on the kinematics of Meinel in Germany; both theoretical and practical research has been conducted in this area. The theory and methods of coordination training were compiled by Watahiki (1990) in Japan, and Japanese researchers have also conducted studies based on German theory (Kano, 2016). According to Azumane et al. (2002), commenting on Araki's unique understanding of "koordination" (coordination), the essence of coordination lies in coordinating the stability of movements and disruptions to that stability; coordination is created by synthesizing psychological and physical stimuli, while movement is created by the environment and stimuli. Azumane (2015) described coordination ability as the ability of the nervous system to move the body skillfully enough to perform rationally and effectively, coordinating the motor nerves that contribute to muscle and nerve coupling through basic motor sensations. In other words, coordination ability achieves harmony between psychological trial-and-error elements, thus facilitating movement and motor elements that improve new movements. Both coordination and integration ability and coordination ability are motor abilities that allow for skillful movement; the development of nervous system functions makes it possible to control the muscles. In addition, coordination and integration ability, alongside motor ability (which supports coordination ability), interacts with psychological factors. The current study considers both coordination and integration ability and coordination ability as a common concept, which helps to realize both motor skills and psychological development.

According to a report by Kozuka et al. (2010), three months of coordination training for young children increased their coordination and integration ability, as measured by repetitive lateral jumps (agility) and standing long jumps (coordination, instantaneous force). According to Azumane (2015), the type and development of movement in coordination exercises can enhance coordination ability, and as frequent changes in a short period of time provide various stimuli, coordination exercise makes it interesting to move, thus ensuring an adequate amount of physical exercise. These past studies have elucidated the effect of coordination exercises on coordination, integration, and motor ability via coordination ability. Exercise in early childhood and school, when the nervous system is developing quickly, promotes the acquisition of skillful movements. For this reason, guidance, coordination methods, and exercises have been developed to enhance coordination ability (Azumane, 2006; 2015). 
In Japan, where the decline in basic motor skills is considered a problem, early childhood exercise guidelines have been created. The "movement diversification" described in such guidelines aims to increase the types of basic movement that children acquire through play and life experiences, leading to enhanced body movement. Through "movement refinement," children learn to refine their basic movements. Their initially awkward movements become less immature as they accumulate appropriate exercise experience. By accumulating both "movement diversification" and "movement refinement" through body-moving forms of play, children acquire smooth movements while increasing their physical strength and motor skills. In addition, accumulated experience of movement diversification and refinement is thought to improve children's motivation and interest in various activities, nurturing their social skills by engaging with the surrounding environment.

A series of studies on the development of physical expressiveness by Wakamatsu $(1989 ; 1990 ; 1993)$ shows that three-year-old children have larger movements, more diverse expressions, and more involvement with other children through their caretakers. They also experience longer periods of enjoyment as they become more expressive. Four-year-old children have been observed moving rhythmically, using two kinds of trunk movements in tandem, interacting using space, and moving emotionally. Five-year-old children have been observed to enjoy rhythmic movements in groups of five or six people; their movements show spatial spread due to location shifts and elevation differences. These children use their entire bodies in rhythmic movements with good timing. Based on these observations, the authors suggest that young children's physical expression skills increase as they grow older, accompanied by physical and social development. In other words, research shows that young children's movements become more synchronized with others as they age. As they have more opportunities to communicate with other children, their movements become richer and more enjoyable, while their spatial range of movement expands. According to Furuichi (1996), sharing rhythms in synchronization with other children (for example, through rhythmic dance) gives children both psychological and physical pleasure, eliciting spontaneous movement, and promoting children's mental development as they move together. According to Kameyama (2008), the expressive activity of rhythmic dancing gives five- and six-year-old children an opportunity to enrich their expressive ability and movement. As these experiences increase children's motivation to move, their experience evolves from well-timed movements to a range of movements. Young children demonstrate a growing interest in moving spontaneously-for example, by moving with another person or expressing themselves to others through movements. In other words, the experience of rhythmic movement in early childhood appears to free the mind and body, nurturing a positive attitude in young children who engage in such activities. By physically expressing themselves, young children seem to expand their range of activities and to liberate their minds and bodies by moving in rhythm. In addition, movement diversification helps children enjoy communicating with 
other children. As children become involved in groups, their movements are enriched, promoting the development of social skills.

The current study has developed and implemented an exercise program focused primarily on rhythmic play, using coordinated movements to examine the richness of children's movements. Based on the results of previous studies (Yoshimi \& Katayama, 2019; Yoshimi, 2020a; 2020b), we argue that social development should be quantified and included as an evaluation index in future studies, alongside observational-evaluation items related to wealth of movement.

Therefore, the purpose of this study is to quantify communication through movement as the development of sociality using evaluation indexes and to clarify the changes by grade as well as define physical-expression ability as the development of social skills used to communicate with other children through movement. These skills are developed through an exercise program that leads to movement enrichment. The current study observes changes in social skills and movement before and after the rhythmic-play exercise program. It clarifies how the social properties of young children change, and how their movement becomes richer as they age through the movement program.

\section{Methods}

\subsection{Study Participants}

The study participants were 106 young children attending a private preschool. The group consisted of 29 three-year-old children (mean age and standard deviation at initial measurement 49.2 months \pm 4.00: 10 boys and 20 girls), 44 four-year-old children (mean age and standard deviation at initial measurement 62.84 months $\pm 3.35: 22$ boys and 22 girls), and 33 five-year-old children (mean age at initial measurement 73.48 months \pm 3.26 : 49 boys and 58 girls). Twenty-one children attended a five-year-old class that was canceled on the measurement date; those who were absent or refused to participate were excluded from the study. The participating preschool had a yard and nursery room attached to the preschool building. This study was conducted with the approval (approval number: 2019-73) of the Institutional Review Board of Kyoto Institute of Technology. The purpose of the research was explained in advance to the director, preschool teachers, and parents and guardians of potential research participants. Written consent was obtained from the parents or guardians of the participants.

\subsection{Procedure}

A non-exercise intervention period and an exercise intervention period of four weeks were set for each research participant. The exercise intervention period took place after the non-exercise intervention period (Figure 1). During the non-exercise intervention period, no specific exercise program was performed, while during the exercise intervention period, a coordination-exercise program focusing on rhythmic play was performed 20 times for six minutes per day. To 


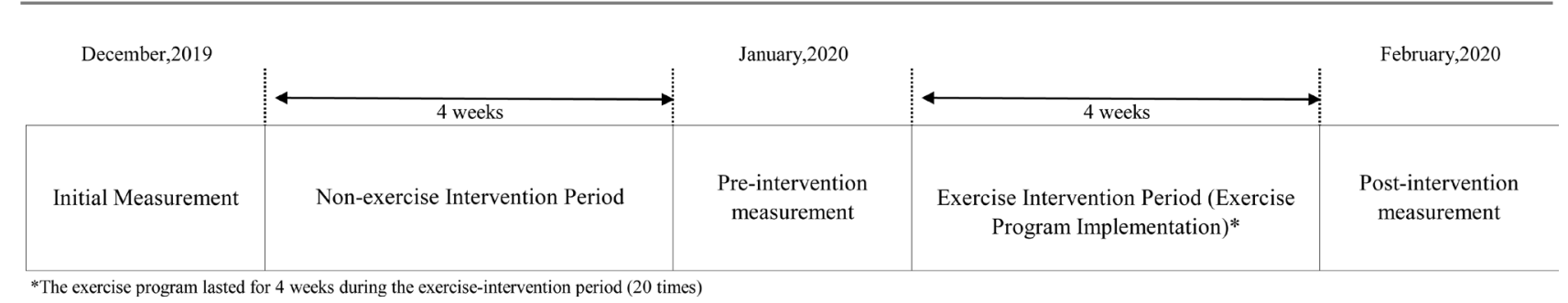

Figure 1. Measurement protocol.

verify changes in each period, we performed initial measurements before the start of the non-exercise intervention period, pre-intervention measurements after the end of the non-exercise intervention period, and post-intervention measurements after the end of the exercise intervention period. This method was based on the study by Umezaki et al. (2013). The implementation period was December 2019 to February 2020.

\subsection{Exercise Program}

The exercise program consisted of six events: walking, jumping, rotation, support, rhythm, and balance. The movements (which included the basic movements shown in "movement to balance the body") included standing, sitting, and rotating. In the "movement to move the body," walking, running, hopping, and jumping were incorporated, as shown under "diversification of movement" in the early childhood-movement guidelines. The content was designed to ensure that the seven kinds of coordination skills-orientation, adaptation, rhythm, reaction, balance, coupling, and differentiation-could be learned equally well (Table 1). The tempo of the music used in the exercise programs was allegretto. For each item, movements were developed in accordance with the participants' level of proficiency, so that their interest in the exercise program would grow without them getting bored. The methods, movements developed for each item, and ways of practicing the movements were explained to the caregivers in advance. The exercise program took place in the playroom or the school yard, where participants could move their bodies sufficiently in line with their daily schedules, weather, and school events. The content of the exercise program is shown in Figure 2.

\subsection{Test Variables}

\subsubsection{Motor Skills Test}

In this study, items capable of measuring coordination and integration, both of which develop to a remarkable extent in early childhood, were used as the motor skills test. Continuous two-foot jumping was chosen as the index of agility. Japanese Hopscotch, ken-ken-pa, was chosen as an index of muscle endurance and balance. According to Higashiyama (1992), the dynamic rhythm of ken-ken-pa is deeply associated with coordination and integration for boys and girls alike. Regarding measurement methods, the continuous two-footed jumps were performed in accordance with the motor-skills survey method for young children 
Table 1. Exercise program events and coordination classification (Revised based on Azumane, 2006, Umezaki et al., 2013, and the Early Childhood Exercise Guidelines, 2012).

\begin{tabular}{|c|c|c|c|c|c|c|c|c|c|c|c|}
\hline \multirow[b]{2}{*}{ Event } & \multirow[b]{2}{*}{$\begin{array}{c}\text { Movement } \\
\text { Development }\end{array}$} & \multirow[b]{2}{*}{$\begin{array}{l}\text { Item } \\
\text { (Azumane, } \\
\text { 2006) }\end{array}$} & \multirow[b]{2}{*}{ Method (Azumane, 2006) } & \multicolumn{7}{|c|}{$\begin{array}{l}\text { Coordination Ability } \\
\text { (Azumane, 2006) }\end{array}$} & \multirow{2}{*}{$\begin{array}{c}\text { Early } \\
\text { childhood } \\
\text { exercise } \\
\text { guidelines } \\
\text { "Diversificat } \\
\text { ion of } \\
\text { movements" }\end{array}$} \\
\hline & & & & 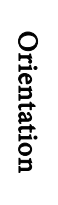 & 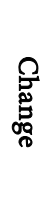 & 窎 & 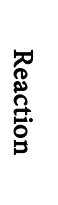 & 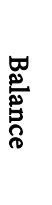 & 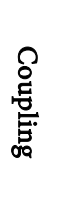 & 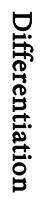 & \\
\hline \multirow{4}{*}{$\begin{array}{l}\text { Walk/ } \\
\text { Jump }\end{array}$} & 1 & $\begin{array}{l}\text { High-knee } \\
\quad \text { walk }\end{array}$ & $\begin{array}{l}\text { Walk with knees raised high while swinging the arms } \\
\text { forward and backward and moving left, right, front, } \\
\text { and back. }\end{array}$ & & & $\bigcirc$ & & $\bigcirc$ & $\bigcirc$ & & Walk \\
\hline & 2 & $\begin{array}{l}\text { High-knee } \\
\text { run }\end{array}$ & $\begin{array}{l}\text { Run with knees raised high while swinging the arms } \\
\text { forward and backward and moving left, right, front, } \\
\text { and back. }\end{array}$ & & & $\bigcirc$ & & $\bigcirc$ & $\bigcirc$ & & Run \\
\hline & 3 & Skip 1 & $\begin{array}{l}\text { Move back and forth and left and right while } \\
\text { skipping. Skipping is performed while clapping } \\
\text { hands. }\end{array}$ & & O & ○ & & O & $\bigcirc$ & O & Hop \\
\hline & 4 & Skip 2 & $\begin{array}{l}\text { Skip while jumping slowly and high. A backward } \\
\text { skip is also performed. }\end{array}$ & & O & $\bigcirc$ & $\bigcirc$ & $\bigcirc$ & $\bigcirc$ & $\bigcirc$ & Hop \\
\hline \multirow{4}{*}{ Jump } & 1 & $\begin{array}{l}\text { Two-footed } \\
\text { jump } 1\end{array}$ & $\begin{array}{l}\text { Perform two-footed jumps forward, backward, left, } \\
\text { and right. }\end{array}$ & & $\bigcirc$ & $\bigcirc$ & & O & $\bigcirc$ & & Jump \\
\hline & 2 & $\begin{array}{l}\text { Two-footed } \\
\text { jump } 2\end{array}$ & $\begin{array}{l}\text { Perform two-footed jumps forward, backward, left, } \\
\text { and right, with varying distance. }\end{array}$ & & $\bigcirc$ & $\bigcirc$ & & O & $\bigcirc$ & & Jump \\
\hline & 1 & $\begin{array}{l}\text { Ken-ken-pa } \\
\text { jump } 1\end{array}$ & Perform ken-ken-pa rhythmically. & & O & $\bigcirc$ & & O & $\bigcirc$ & & Hop \\
\hline & 2 & $\begin{array}{l}\text { Ken-ken-pa } \\
\quad \text { jump } 2\end{array}$ & $\begin{array}{l}\text { Perform ken-ken-pa rhythmically with the "ken } \\
\text { steps" placed on the floor. }\end{array}$ & ○ & $\bigcirc$ & $\bigcirc$ & $\bigcirc$ & O & $\bigcirc$ & $\bigcirc$ & Hop \\
\hline \multirow[b]{2}{*}{$\begin{array}{l}\text { Jump/ } \\
\text { Rotation }\end{array}$} & 1 & Jump turn 1 & From a standing position, repeat a 180 -degree turn. & & $\bigcirc$ & & & $\bigcirc$ & $\bigcirc$ & & Rotate \\
\hline & 2 & Jump turn 2 & $\begin{array}{l}\text { While moving forward jumping turn } 1 \text { twice. At the } \\
\text { third jump, which can be } 180 \text { or } 360 \text { degrees, move } \\
\text { to the left or right continuously. }\end{array}$ & & $\bigcirc$ & O & $\bigcirc$ & O & $\bigcirc$ & & Rotate \\
\hline \multirow{2}{*}{$\begin{array}{l}\text { Jump/ } \\
\text { Support }\end{array}$} & 1 & $\begin{array}{l}\text { Rabbit hop } \\
1\end{array}$ & $\begin{array}{l}\text { Attention is paid to the fingers, palms, head, and } \\
\text { eyes. Land ahead of where the hands were } \\
\text { previously. }\end{array}$ & & & O & & O & $\bigcirc$ & & Sit/Jump \\
\hline & 2 & $\begin{array}{l}\text { Rabbit hop } \\
2\end{array}$ & $\begin{array}{l}\text { Attention is paid to the fingers, palms, head, and } \\
\text { eyes. Land ahead of where the hands were } \\
\text { previously. }\end{array}$ & & & $\bigcirc$ & $\bigcirc$ & O & $\bigcirc$ & & Sit/Jump \\
\hline \multirow{2}{*}{$\begin{array}{l}\text { Jump/ } \\
\text { Rhythm }\end{array}$} & 1 & $\begin{array}{c}\text { Rhythm run } \\
1\end{array}$ & Run in a "1, 2, 3" rhythm (triple time). & & $\bigcirc$ & $\bigcirc$ & & $\bigcirc$ & $\bigcirc$ & & Run/Jump \\
\hline & 2 & $\begin{array}{l}\text { Rhythm run } \\
2\end{array}$ & $\begin{array}{l}\text { Perform rhythm run } 1 \text { with varying speed and } \\
\text { rhythm. }\end{array}$ & & O & O & $\bigcirc$ & O & O & & Run/Jump \\
\hline \multirow{2}{*}{$\begin{array}{l}\text { Rhythm/ } \\
\text { Balance }\end{array}$} & 1 & $\begin{array}{c}\text { Cross touch } \\
1\end{array}$ & $\begin{array}{l}\text { (1) Raise the left foot inward and touch it with the } \\
\text { right hand. } \\
\text { (2) Next, touch the right foot with the left hand. }\end{array}$ & & $\bigcirc$ & $\bigcirc$ & & O & & & Stand/Jump \\
\hline & 2 & $\begin{array}{c}\text { Cross touch } \\
2\end{array}$ & $\begin{array}{l}\text { (1) Raise the left foot towards the back diagonally, } \\
\text { and touch it with the right hand. } \\
\text { (2) Touch the right foot with the left hand. }\end{array}$ & & $\bigcirc$ & ○ & & $\bigcirc$ & & & Stand/Jump \\
\hline
\end{tabular}




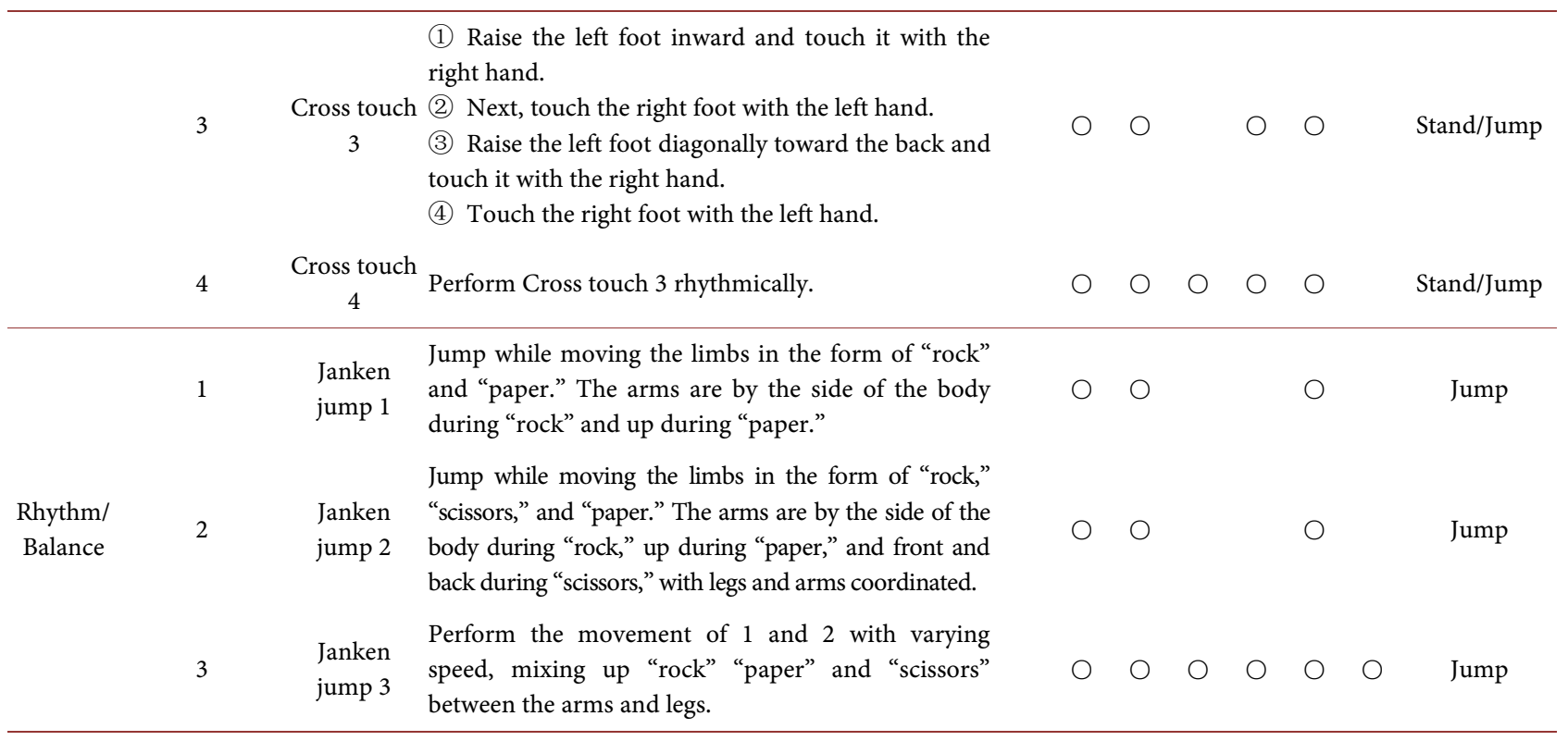

(MEXT, 2012). Ken-ken-pa was performed according to the method developed by Ikeda and Aoyanagi (2010). Given the waiting time and physical fitness burden on research participants during childcare hours, the results were measured through one practice and one actual trial. In the event of failure, the children repeated the trial.

\subsubsection{Observational Evaluation of Physical-Expression Ability}

During the exercise program, the children's movements were videotaped from the side using a digital video camera (SONY Co., Ltd., HDR-CX470). The projected video images were observed and evaluated. The evaluation items were then added and revised, based on Yoshimi (2020a; 2020b)'s evaluation indices and referring to Matsumoto (1992), who clarified the validity of dance structure and function, and Gough (1997), who divided the aim of the movement into four elements to enrich its expression. The observation evaluation of physical-expression ability included three items related to motion, two related to space, two related to dynamics, two related to time, and three related to relationships. The mean was calculated for each of the five categories. Items were evaluated using a 5-point scale, with the following range of responses: "describes very well” ( 5 points), “describes somewhat" (4 points), "neither" ( 3 points), "does not describe well" (2 points), and "does not describe at all" (1 point) (Table 2). The observational evaluation was conducted by two raters with experience in teaching dance to young children. Individual mean scores for the five categories were used to test the inter-rater agreement of the scores.

\subsubsection{Statistical Analysis}

We employed an unpaired t-test to compare the evaluation score means from the observational evaluation of physical expression ability. Where we did not detect any significant difference, we calculated Spearman's correlation coefficients to 


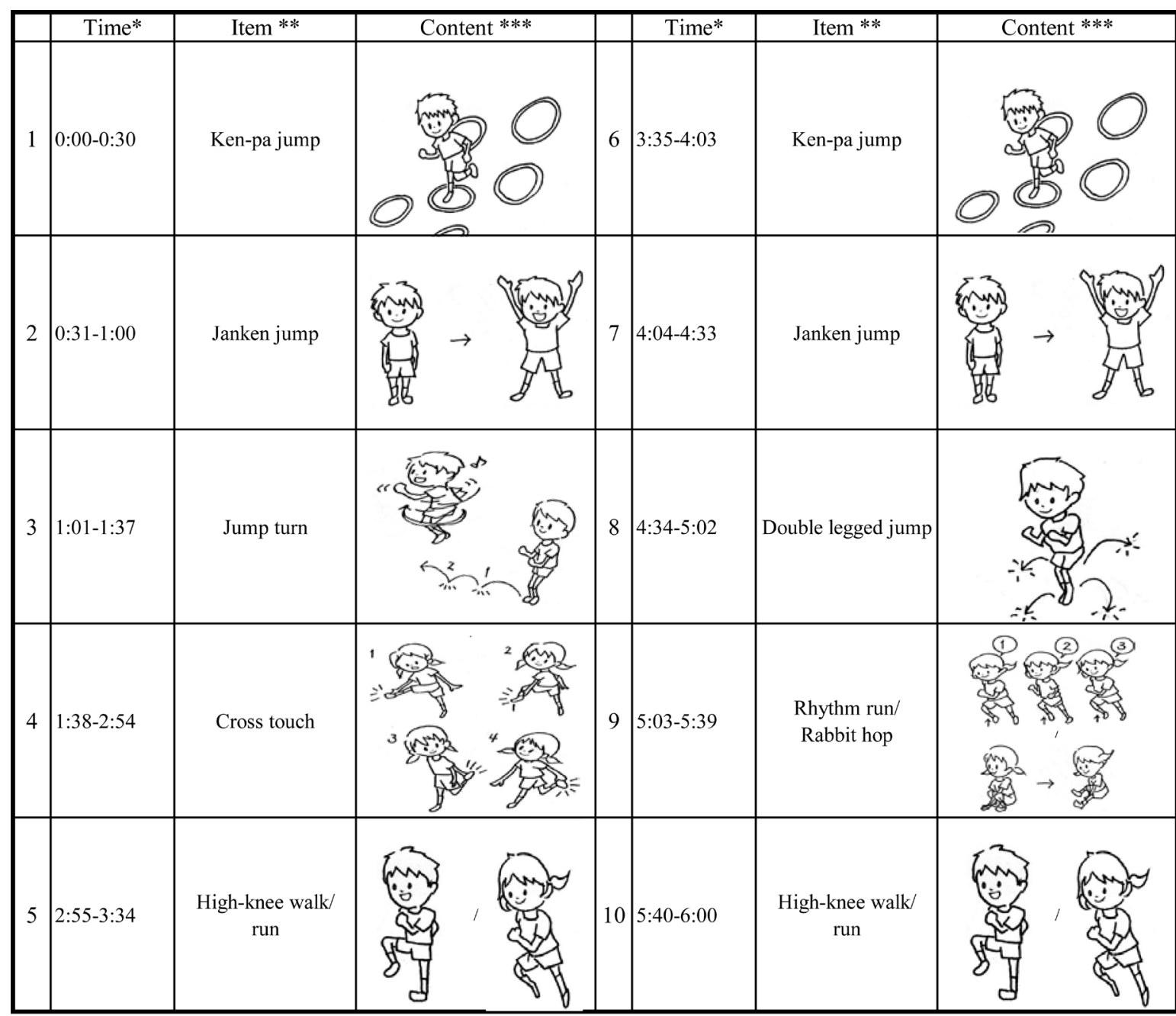

* represents the time allocated to the event, ** represents the item at the first stage of movement development, as described in Table1, and *** represents the methods graphically.

Figure 2. Coordination exercise centered on rhythmic play.

Table 2. Observational items of physical-expression ability.

\begin{tabular}{|c|c|}
\hline Items & \\
\hline \multirow[t]{3}{*}{ Items related to movement } & 1 The whole body is used freely. \\
\hline & 2 Moving in rhythm using the body. \\
\hline & 3 Movements are connected smoothly. \\
\hline \multirow[t]{2}{*}{ Items related to space } & 4 Moving with high and low movements. \\
\hline & 5 Moving in various places by figuring out how to use the space. \\
\hline \multirow[t]{2}{*}{ Items related to dynamics } & 6 Enjoying changes in movement, such as fast movement, slow movement, and stopping. \\
\hline & 7 Moving from the core of the body. \\
\hline \multirow[t]{2}{*}{ Items related to time } & 8 Continued rhythmic movement, without interrupted attention (interval length). \\
\hline & 9 Repetitive motions with a change in form and speed. \\
\hline \multirow[t]{3}{*}{ Items related to relationships } & 10 Moving while aligning with each others' rhythms. \\
\hline & 11 Moving while looking at others. \\
\hline & 12 Interaction with others through movement. \\
\hline
\end{tabular}


investigate the concordance of assessment trends between the raters. We performed two-factor analyses of variance with repeated measures to examine changes in each measurement item at three different times (initial, pre- and post-intervention) as well as the interaction of measurement time and age level. Multiple Tukey's comparison tests were used when we detected a main effect on the time of measurement. Statistical analyses were performed using IBM SPSS Statistics 25 , with a significance level of $5 \%$.

\section{Results}

The physical changes per month, calculated from height and weight measurements taken twice at the preschool (in January and February) were $+0.28 \mathrm{~cm}$ (height) and $+0.07 \mathrm{~kg}$ (weight); $0.31 \mathrm{~cm}$ (height) and $+0.1 \mathrm{~kg}$ (weight); and +1.1 $\mathrm{cm}$ (height) and $+0.21 \mathrm{~kg}$ (weight) for children aged three, four, and five, respectively. For both boys and girls, monthly changes in height and weight were similar to age measures in the Infant Physical Growth Survey (MHLW, 2010). This shows that the study participants constituted a sample with average physical characteristics. Before and after the exercise-intervention period (pre- and post-intervention), the monthly fitness change calculated using measurements from the continuous two-footed jump and ken-ken-pa, showed a reduction by 1.86 seconds and 1.48 seconds among three-year-old children for the continuous two-footed jump and ken-ken-pa, respectively. Among four-year-old children, the continuous two-footed jump was reduced by $1.11 \mathrm{~s}$ and ken-ken-pa by 0.58 seconds. Among five-year-old children, the continuous two-footed jump was reduced by 0.12 seconds, and the ken-ken-pa by 0.38 seconds.

In the observation-evaluation scores for physical-expression ability, we found no statistically significant difference between the two raters' means. The correlation coefficient of the raters' motion-richness observation scores was 0.823 for motion items, 0.827 for spatial items, 0.874 for dynamic items, 0.856 for time-related items, and 0.863 for the relationship items; in all cases, there was a significant positive correlation $(p<0.05)$.

\subsection{Impact on Motor Skills}

A two-factor analysis of variance (with age groups and time of measurement) showed a significant interaction between the two-leg continuity and traversal factors $(F=4.95)$. Therefore, we investigated the simple main effects of these factors (Table 3). Following multiple comparison tests, a significant difference was observed among three-year-olds between the initial and pre-intervention measurements, and between the pre- and post-intervention measurements, with the pre-intervention measurement showing the highest value, followed by the post-intervention and initial measurements. Among four-year-olds, a significant difference was found between the pre- and post-intervention measurements. Among five-year-olds, we detected no significant differences between the measurement times. For ken-ken-pa, significant main effects were observed only in 
measurement timing $(\mathrm{F}=15.13)$ and age $(\mathrm{F}=37.92)$. Multiple comparison tests revealed significant differences between the initial and post-intervention measurements and pre-and post-intervention measurements.

\subsection{Effects on Physical-Expression Ability}

A two-factor analysis of variance with measurement timing and age showed an interaction among the relationship items $(F=3.44)$. Therefore, the simple main effects of these factors were examined (Table 3 ). Following multiple comparison tests, significant differences were found between all measured values among three-year-old children. We detected significant differences between the initial and post-intervention measurements or the pre- and post-intervention measurements among four- and five-year-old children. No significant interactions

Table 3. Results of two-factor analyses of variance for the measures.

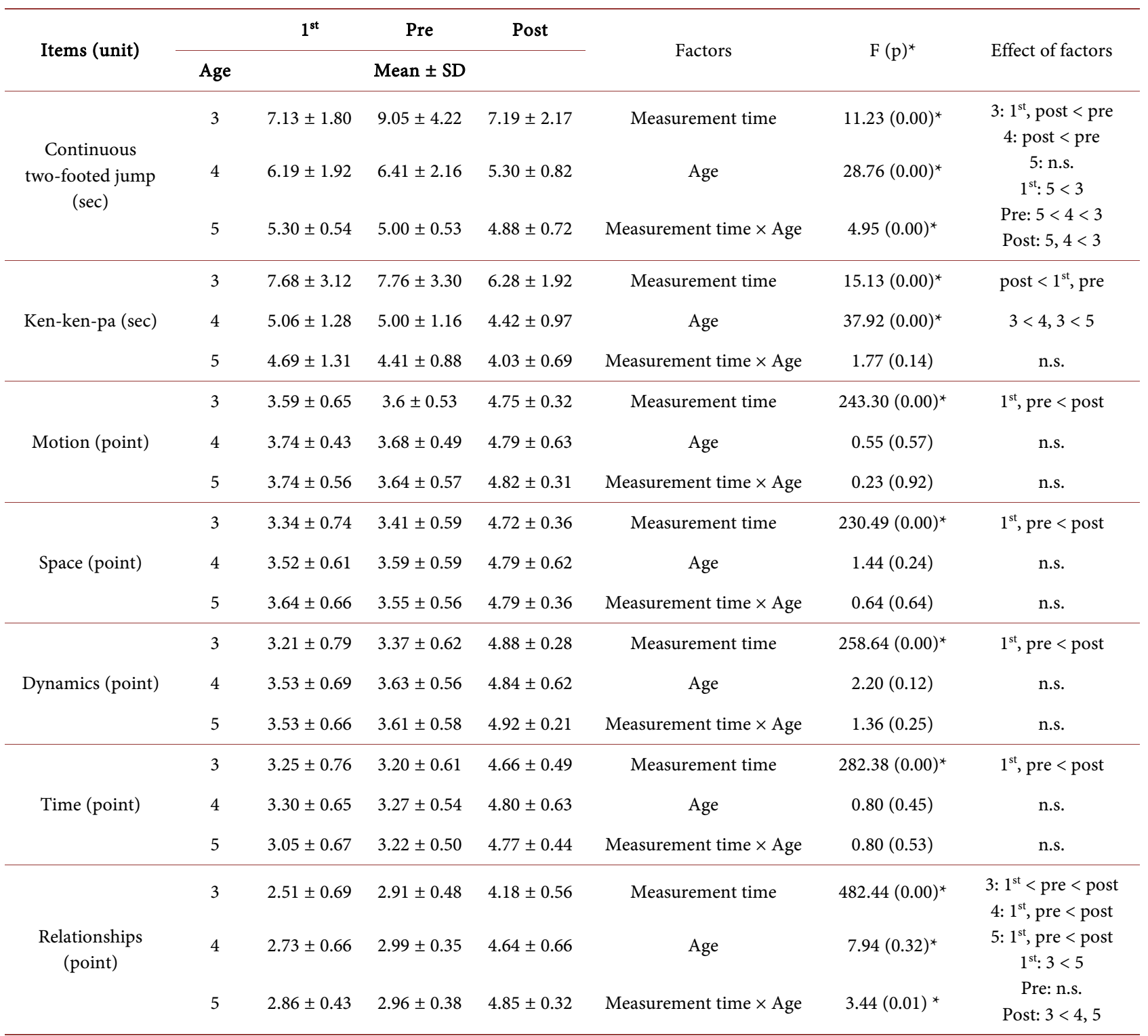


were observed for items related to movement, space, dynamics, or time. Significant main effects were observed only at the time of the measurement. Multiple comparisons showed significant differences between the initial and post-intervention measurements and between pre- and post-intervention measurements.

\section{Discussion}

\subsection{Impact on Motor Skills}

The results of the motor skills test showed that the time to completion was shorter among five-year-old children for the continuous two-footed jump, although the difference was not statistically significant. According to Iwasaki et al. (1984), the degree to which coordination and integration develop shifts significantly for both boys and girls after the age of five. Coordination and integration develop in a relatively gradual way between the ages of 5, 6, and 11. It may therefore be the case that the five-year-old children did not show significant improvement because their speed of development was relatively slow. Improved motor skills are indicated because completion time was reduced, even though the five-year-old children's motor ability improved slowly. We observed a significant difference among the four-year-old children, and motor skills clearly improved. According to Nishiyama et al. (2009), the rate of motor skill development in three-four-year-old children (as measured via the continuous two-footed jump) was greater than the rate among children aged five-six years; their results were similar to those of four-year-old children in the current study. Considering the exercise intervention period, the results showed that four-year-old children were greatly influenced by the exercise program, even in the short term. Among three-year-old children, we detected no improvement in motor skills; their time to completion was not reduced, and their performance did not improve. According to Takatoku (2019), young children who needed only a short time between landing and jumping during switching operations over 10 landings took less time to complete them overall. Therefore, we can conclude that the smoothness of the landing-to-jumping operation affected the overall completion time. It is likely that four- and five-year-old children, who demonstrated significant improvements, reduced their operation time by achieving continuous jumping during the exercise program.

In relation to ken-ken-pa, children in all groups reduced their completion times and improved their motor skills. According to Sasaki (2019), ken-ken-pa involves the challenge of switching between one-leg and two-leg operations in a timely fashion as it combines a one-footed hop and a two-footed jump as well as continuous jumps. Ken-ken-pa requires dynamic balance ability and balance preservation during a short landing period, followed by movement toward the center of gravity in the forward direction. In other words, the exercise program cultivated continuous jumping and dynamic balance ability, resulting in shorter completion times. Sasaki (2019) found that five-year-old children were more proficient at ken-ken-pa jumping and hopping than four-year-old children. We 
found no significant difference between the measured mean of late four-year-old children (born in November), as shown by Ikeda and Aoyagi (2010), and post-intervention measures among four- and five-year-old children in the current study. Similarly, the post-intervention measurements of three-year-old children in the current study showed higher motor skills than the mean measurements of four-year-old children (born in May) in Ikeda and Aoyagi (2010). In other words, children aged three and four in the current study showed more improvement in their motor skills than those aged five. This suggests that participating in the exercise program improved the complicated jumping motion, involving one foot and two feet, and the continuous-switchover motion of children of all ages; thus, the improved motor skills were apparent. Ken-ken-pa clearly enhanced the motor skills of all children. Specifically, three- and four-year-old children experienced greater improvement than five-year-old children.

Based on the above, the impact on motor skills can be described as follows: the exercise program was shown to be effective in improving the motor skills of young children. In relation to continuous two-footed jumps, improved motor skills among five-year-old children seemed likely, while four-year-old children demonstrated clear improvement. In the case of ken-ken-pa, children of all ages improved their motor skills. It was suggested that ken-ken-pa had a greater effect on the motor skills of three- and four-year-old children than on those of five-year-old children. Although we detected age-related differences, the motor skills of all children improved. This study thus demonstrated an opportunity to improve the motor skills of younger children.

\subsection{Effects on Physical-Expression Ability}

When it came to motion, space, dynamics, and time items, we observed no age-related score differences. Our overall observation in the initial measurement showed that the infant was absorbed in imitating the move (e.g., change in movement in the exercise program and movement following the music). In the post-intervention measurement, it was observed that they saw the face of a friend while moving; that the movement was performed while singing a song; and that the movement was synchronized in a wider space. According to the Japan Society of Research on Early Childhood Care and Education (1989), while rhythm scores for activities such as hand-clapping, walking, and galloping to music increase with age, expression scores (based on physical expression) are the same for all ages. Our findings confirm those of the Japan Society of Research on Early Childhood Care Education (1989), revealing no age-related differences in the observation-evaluation scores for movement, space, dynamics, or time in relation to pre-intervention measurements. A significant increase in scores was clear in all age groups when it came to motion, space, dynamics, and time items. The children's movements became richer, regardless of their age. We also inferred that the children were actively engaged in the exercise program, irrespective of age, based on changing observation scores over multiple measurement points. 
Items related to relationship, for which we observed a significant interaction between measurement timing and age, measure the aspect of communication and interaction through movement during enjoyable movement. The fact that we found age-related differences in the initial comparison of three- and five-year-old children indicates that children's awareness of other children increases with age, as measured via the relationship item. According to Parten (1932), such communication through play is consistent with the development of children's social interactions in play, categorized as unoccupied, solitary play, onlooker, parallel-group activity, associative-group play, and cooperative group play. In the initial measurements, children participated in the exercise program in a space equivalent to Parten's (1932) "parallel group activity:" they enjoyed moving individually. During the pre-intervention measurement, they communicated through movement, as in group, "associative-group," and "cooperative group" play. The age-related score differences in the initial measurement, which did not appear during the pre-intervention measurement, suggest that relationship scores improved, regardless of age, as the children learned to communicate through movement during the exercise program. The post-intervention measurement found a significant difference between three- and four-year-olds and between three- and five-year-olds. The scores increased in all age groups. At the post-intervention stage, children were observed to interact through movement while enjoying play through the exercise program. Children also synchronized with each other's rhythm; many older children engaged in more active behaviors, such as touching their friends' shoulders and talking to each other while exercising. These interactions also revealed age-related differences between three-, four-, and five-year-olds. These differences were consistent with the characteristics of young children's play, which evolved from one-person play to group play as children got older. The overall effect of the exercise program on physical expression ability can be summarized as follows: the present study showed that the exercise program improved the physical expression ability of young children. In addition, communication through movement during the exercise program elicited active behaviors, causing children to demonstrate a desire to interact with other children, regardless of age, thus advancing their social development.

\section{Conclusion}

In the current study, children's movements changed after an exercise program focused on rhythmic play. This research examined the age-related motor skills and physical-expression ability of young children, focusing on how the social properties of young children changed and whether their movements became richer following the exercise program.

- Motor skills. An improvement in motor skills was shown in four- and five-year-old children, and a partial improvement in motor skills was observed in three-year-old children. Although the children's motor skills in- 
creased, we observed age-related differences in the types of effects. It became clear that children as young as three-four years greatly improved their motor skills by engaging in the exercise program.

- Body expression ability. A significant increase in this ability was observed in all age groups. The items on motion, space, dynamics, and time increased to a similar degree, regardless of age. Regarding the relationship items, we detected age-related differences in the initial and post-intervention measurements, while we did not find any differences in the pre-intervention measurements. Regarding physical-expression ability, children in older age groups began to show awareness of other children. The number of times children tackled the exercise program affected the relationship items, regardless of age.

Based on the above results, the present study found that participating in a coordination exercise program designed for young children and based on rhythmic play strengthened the motor skills and body-expression ability of young children. By working on the exercise program, the desire to move with the caregiver and other children and to interact with someone was elicited as a movement. It was shown that while the exercise program was undertaken, the voluntary activities of young children were encouraged, leading to the social development of items related to relationships. Thus, the current study shows that exercise programs can enhance young children's motor skills and body-expression ability, enriching their movements and drawing out age-transcending spontaneous behaviors from young children via social development. At daycare sites, it is expected that group exercise programs will mutually enhance athletic ability and physical expression ability and encourage infants to take voluntary actions through movement.

\section{Acknowledgements}

We would like to express our deepest gratitude to the preschool teachers and children who participated in this study.

\section{Conflicts of Interest}

The authors declare no conflicts of interest regarding the publication of this paper.

\section{References}

Azumane, A. (2006). 65 Coordination Exercises That Change Physical Education Classes: Integrated and Scientific Teaching Methods for the Mind and Body. Tokyo: Meijitosho Shuppan Corporation.

Azumane, A. (2015). Coordination Exercise for Young Children that Improves Motor Skills While Having Fun. Tokyo: Meijitosho Shuppan Corporation.

Azumane, A., Araki, H., \& Watahiki, K. (2002). Round-Table Discussion Coordination Training: Based on the Contents of the Leipzig Workshop (Special Topic: Coordination Training-with the Latest Information in Germany). Monthly Training Journal, 24, 
12-28.

Early Childhood Exercise Guidelines (2012). Guidelines for Early Childhood Physical Activity (pp. 123-132). Tokyo: Nihon Education Books

Evridiki, Z., Aggeliki, T., \& Vassiliki, D. (2004). The Effects of a Developmentally Appropriate Music and Movement Program on Motor Performance. Early Childhood Research Quarterly, 19, 631-642. https://doi.org/10.1016/j.ecresq.2004.10.005

Furuichi, H. (1996). A Consideration of Many Sides in Body Expression Activities in Children. Educare, 16, 19-25.

Gough, M. (1997). In Touch with Dance (Translated by M. Tamagawa, pp. 19-31). Tokyo: Tamagawa University Press.

Higashiyama, A. (1992). Examination of Factors Associated with Motor Coordination Ability. Scientific Reports of Shiga Prefectural Junior College, 41, 75-80.

Ikai, M. (1963). Introduction to Exercise Physiology (Fifth Revision, pp. 143-149). Tokyo: Kyorin Shoin.

Ikai, M. (1972). Coordination and Integration: Its Physiological Considerations (Special Issue on Coordination and Integration). Journal of Health, Physical Education, and Recreation, 22, 5-10.

Ikeda, T., \& Aoyagi, O. (2010). Development and Gender Difference in Innate Potential Motor Ability in Early Childhood: Relationship between the Motor Performance Score and Characteristics of Test Items. Japan Journal of Physical Education, Health and Sport Sciences, 55, 441-452. https://doi.org/10.5432/jjpehss.09068

Iwasaki, Y., Uemura, T., \& Ohashi, Y. (1984). Development of Coordination and Integration in Young Children: Relationship between Sex Difference and Other Factors. Early-Childhood Education Association of Japan Annual Convention, 37, 134-135.

Japan Society of Research on Early Childhood Care and Education (1989). Conditions Affecting the Sense of Rhythmic Expression of Young Children. In Expression and Childcare: Research on Early-Childhood Care and Education in Japan, 1989 Edition Part IV. Expression of Young Children and Environment/Conditions (pp. 116-126). Tokyo: Froebel-kan.

Kameyama, Y. (2008). Research Concerning the Introduction of Dance and Movement of Expression into Early-Childhood Education: In the Context of Rhythmic Dance. Bulletin of Nippon Sports Science University, 37, 97-106.

Kano, H. (2016). Theoretical Basis of Coordination Study in Early Childhood. Bulletin of the Graduate School of Human Development, Aichi Prefectural University, 7, 51-64.

Kozuka, K., Kuga, A., \& Watanabe, T. (2010). Implementation of Coordination Training Targeted for Preschool Children. A Case Study at Mizugidai Daycare in Hanno City. Surugadai University Rongo, 41, 131-144.

Matsumoto, C. (1992). Dance Education 1. Principles of Dance Education. Tokyo: Tokuma Shoten Publishing Co. Ltd.

MHLW Ministry of Health, Labor and Welfare (2010). National Growth Survey on Preschool Children. https://www.mhlw.go.jp/stf/houdou/0000042861.html

Ministry of Education, Culture, Sports, Science and Technology (2002). Comprehensive Measures for Improving Children's Physical Fitness (Report).

https://www.mext.go.jp/b_menu/shingi/chukyo/chukyo0/toushin/021001a.htm\#g00

Ministry of Education, Culture, Sports, Science and Technology (2012). Motor Skills Survey of Young Children (p. 53).

https://www.mext.go.jp/a_menu/sports/undousisin/1319772.htm

Nishiyama, T., Nomura, I., Suga, N., Sato, T., \& Oishi, K. (2009). 2006 Report on Motor 
Skills Measurement of Young Children. Kanagawa:: Kanagawa Prefectural Board of Education, Sports Division and Nippon Sport Science University. https://www.nittai.ac.jp/department/human-performance/gaiyo.pdf

Parten, M. B. (1932). Social Participation among Preschool Children. Journal of Abnormal and Social Psychology, 27, 243-269. https://doi.org/10.1037/h0074524

Sasaki, R. (2019). Development of Rhythmic Coordinated Movements in Preschool Children. Research Project Number 16K01884. https://kaken.nii.ac.jp/ja/file/KAKENHI-PROJECT-16K01884/16K01884seika.pdf

Takai, K. (2007). Recent Trends in Research on Physical Coordination and Integration in Children (2nd Report). Annual Report of the Faculty of Education. Bunkyo University, 41, 83-94.

Takatoku, N. (2019). The Effect of Two-Footed Synchronism on Spatiotemporal Body Control While Hopping in Young Children. Japanese Journal of Physical Education, Health, Sport Sciences, 64, 665-674. https://doi.org/10.5432/jipehss.19037

Takenawa, M., Takeda, T., Kikuchi, H., \& Nakagawa, K. (2008). Teaching Program for Kids in Aerobics. Bulletin of the Continuing Education Research Institute. Hokkaido Asai Gakuen University, 11, 213-227.

Tomita, H., Otobuchi, R., \& Matsushima, A. (2014). The Effect of an Exercise Program that Includes Rhythmic Motion on the Sense of Rhythm and Physical Fitness of Young Children. Bulletin of the Shizuoka Institute of Science and Technology, 22, 51-56.

Ueda, K. (2008). Coordination Training and "Physical Ability". Japan Journal for the Pedagogy of Physical Education, 24, 25-30.

Umezaki, S., Nakatani, T., Yamamoto, D., Nakasuka, T., \& Hashimoto, M. (2013). Effects of Coordination Exercise on the Motion Capacity of Preschool Children: Quantitative and Qualitative Changes in Throwing and Catching Ability. Japan Journal of Human Growth and Developmental Research, 59, 27-40.

Wakamatsu, M. (1989). Development of the Physical-Expression Ability of 4-Year-Old Children. Shiraume Gakuen Junior College Bulletin, 25, 45-56.

Wakamatsu, M. (1990). Development of the Physical Expressive Ability of 5-Year-Old Children. Shiraume Gakuen Junior College Bulletin, 26, 69-80.

Wakamatsu, M. (1993). Development of the Physical-Expression Ability of 3-Year-Old Children. Shiraume Gakuen Junior College Bulletin, 29, 49-61.

Watahiki, K. (1990). Coordination Training-The Secret of East Germany's Strength. Tokyo: Shin Taiiku Sha.

Yoshimi, E. (2020a). Study on the Cooperative Movement of Infants: Focus on the Richness of Movement Seen in Rhythmic Movements (2). Annual Reports of Studies. Tokiwakai Junior College, 48, 87-102.

Yoshimi, E. (2020b). Study on the Cooperative Movement of Infants: Focus on the Richness of Movement Seen in Rhythmic Movements (3). Tokiwakai Junior College Early-Childhood Education Journal, 36, 30-43.

Yoshimi, E., \& Katayama, H. (2019). Study on the Cooperative Movement of Infants: Focus on the Richness of Movement Seen in Rhythmic Movements (1). Tokiwakai Junior College Early-Childhood Education Journal, 35, 58-71. 